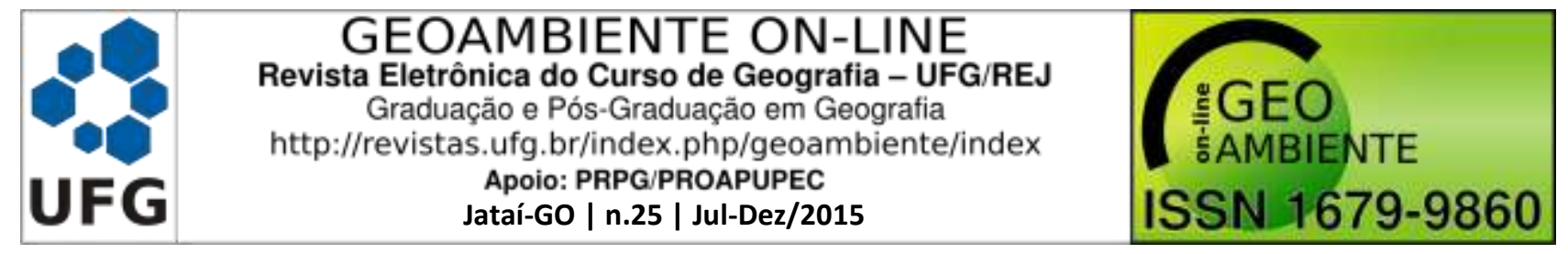

\title{
EROSIVIDADE DAS CHUVAS (R) NOS MUNICÍPIOS DE CASTELO DO PIAUÍ E JUAZEIRO DO PIAUÍ, NO ESTADO DO PIAUÍ (BRASIL)
}

\author{
Francílio de Amorim dos $\operatorname{Santos}^{1}$, Cláudia Maria Sabóia de Aquino ${ }^{2}$
}

(1 - Instituto Federal de Educação, Ciência e Tecnologia do Piaú / Campus Piripiri, Mestre em Geografia, francilio.amorim@ifpi.edu.br; 2 - Universidade Federal do Piauí / Campus Ministro Petrônio Portela, Doutora em Geografia, cmsaboia@gmail.com)

Resumo: O objetivo do presente estudo foi estimar a Erosividade das chuvas (R) nos municípios de Castelo do Piauí e Juazeiro do Piauí, por meio dos dados dos postos meteorológicos da SUDENE. Para estimar o fator R foram utilizados os dados de precipitação das 13 estações pluviométricas da Superintendência do Desenvolvimento do Nordeste (SUDENE). Os referidos dados tiveram suas falhas corrigidas através do Método de Ponderação Regional e foram manuseados no Sistema de Informação Geográfica (SIG) ArcGIS 10.2. Desse modo, foi possível estimar que 51,1\% dos municípios estudados possuem taxas pluviométricas situadas entre 1.100 a $1.200 \mathrm{~mm}$ e em $11,9 \%$ a erosividade variou de muito baixa a baixa erosividade, $74,7 \%$ da área de estudo foram enquadradas nas classes de alta a muito alta erosividade, evidenciando assim fragilidade climática natural constituindo-se fator limitante ao desenvolvimento de atividades agropecuárias. Tais dados possibilitam o desenvolvimento de planejamentos físico territoriais, almejando o mínimo impacto possível à dinâmica ambiental, contudo ressalta-se o complemento desta analise com dados relativos à declividade, tipos de solos, fisionomia da cobertura vegetal e ainda dos tipos de usos da área de estudo objetivando uma analise da fragilidade ambiental da área de modo mais completa.

Palavras-chave: Precipitações. Método Indireto. Erosão dos solos. Geoprocessamento.

\section{EROSIVITY OF RAINFALL (R) IN THE MUNICIPALITIES OF CASTELO DO PIAUÍ AND JUAZEIRO DO PIAUÍ, IN PIAUÍ STATE (BRAZIL)}

Abstract: The aim of this study was to estimate the rainfall erosivity (R) in the counties of Castelo do Piauí and Juazeiro do Piauí, through the data of meteorological stations SUDENE. To estimate the rainfall factor $\mathrm{R}$ were used data of the thirteen (13) rainfall stations of

Artigo recebido para publicação em 24 de Agosto de 2015

Artigo aprovado para publicação em 23 de Dezembro de 2015 


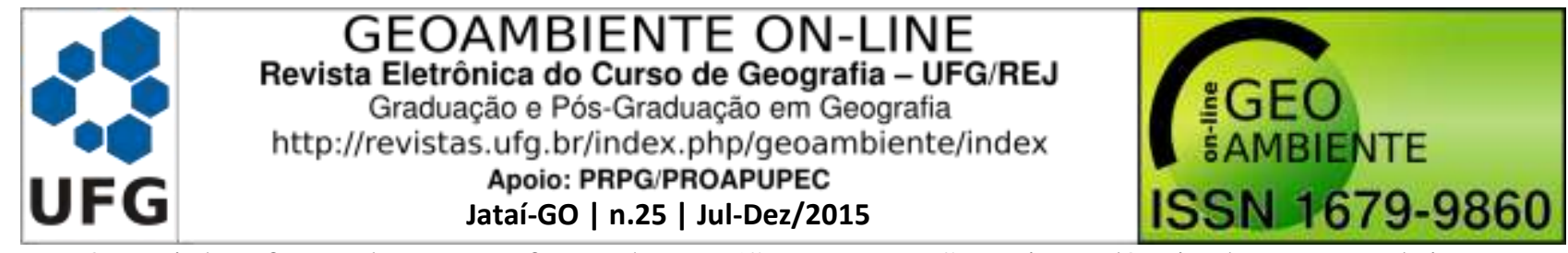

Oversight of Development of Northeast (SUDENE - Superintendência do Desenvolvimento do Nordeste). The figures had their failures corrected by the Regional Weighting Method and were handled in Geographic Information System (GIS) ArcGIS 10.2. Thus, it was possible to estimate that $51.1 \%$ of the counties studied have located rainfall rates between 1100-1200 $\mathrm{mm}$, and $11.9 \%$ erosivity ranged from very low to low erosivity, $74.7 \%$ of the study area were classified in the high to very high erosivity classes, thus showing natural climate fragility constituting limiting factor to the development of agricultural activities. These data enable the development of regional physical planning, targeting the least possible impact to the environmental dynamics, but it is noteworthy complement of this analysis with data that relate to declivity, soil types, physiognomy of the vegetation cover and even the types of uses of area study aimed at an analysis of the area environmental fragility of the most complete way.

Keywords: Precipitation. Indirect Method. Soil erosion. Geoprocessing.

\section{EROSIVIDAD DE LA LLUVIA (R) EN LOS MUNICIPIOS DE CASTELO DO PIAUÍ Y JUAZEIRO PIAUÍ, EN EL ESTADO PIAUÍ (BRASIL)}

Resumen: El objetivo de este estudio fue estimar la erosividad de la lluvia (R) en los municipios de Castelo de Piauí y Juazeiro de Piauí, a través de los datos de las estaciones meteorológicas SUDENE. Para estimar los datos de precipitación del factor R se utilizaron las 13 estaciones pluviométricas de SUDENE (Superintendencia del Desarrollo del Nordeste). Los referidos datos tuvieron sus errores corregidos por el Método Regional de ponderación y se manejaron en el Sistema de Información Geográfica (SIG) de ArcGIS 10.2. Así, fue posible estimar que el 51,1\% de los municipios de Castelo de Piauí y Juazeiro de Piauí han situado las tasas de lluvia entre 1100-1200 mm y en 11,9\% la erosividad varió de muy bajo a bajo erosividad, $74,7 \%$ del área de estudio se clasificaron en las clases altas a muy alta erosividad, demostrando así la fragilidad natural del clima constituyéndose factor limitante para el desarrollo de las actividades agrícolas. Estos datos permiten el desarrollo de la planificación física territoriales, apuntando el menor impacto posible a la dinámica del medio ambiente, pero vale resaltar el complemento de este análisis con los datos relacionados a la declividad, tipos de suelo, la fisonomía de la cubierta vegetal e incluso los tipos de usos de la zona estudio objetivando un análisis de la fragilidad del medio ambiente de la zona de manera más completa.

Palabras clave: Precipitación. Método indirecto. Erosión de suelo. Geoprocesamiento.

\section{INTRODUÇÃO}




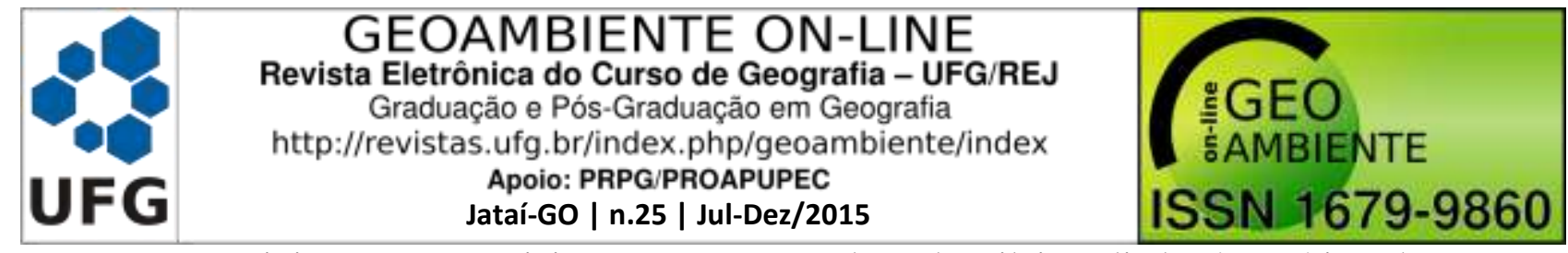

Precipitações torrenciais comuns no Nordeste brasileiro aliadas às práticas humanas realizadas de modo inadequado são prejudiciais ao meio ambiente. A concentração das precipitações em solos desprotegidos, principalmente, devido às práticas agropecuárias sem o devido manejo e proteção da cobertura vegetal deixa os solos vulneráveis à ação da energia cinética das gotas das chuvas.

Nesse contexto, torna-se de grande importância estimar, por meio de métodos indiretos, o potencial de Erosividade das chuvas (R) em Castelo do Piauí e Juazeiro do Piauí. O referido potencial está relacionado, de acordo com Lombardi Neto e Moldenhauer (1992), à perda de solo por unidade de área esperada durante uma chuva ao cair em área sem cobertura vegetal. Nesse sentido, é possível estimar o potencial que a chuva possui em degradar os solos em áreas desprovidas de vegetação ou com cobertura vegetal de pequeno porte ou raquítica, como é o caso dos municípios em estudo.

O objetivo do presente estudo foi estimar a Erosividade das chuvas (R) nos municípios de Castelo do Piauí e Juazeiro do Piauí, por meio dos dados das estações pluviométricas da Superintendência do Desenvolvimento do Nordeste (SUDENE, 1990). Para tal fim, elaboraram-se os seguintes objetivos específicos: 1) mensurar, através de método indireto, a erosividade das chuvas da área dos referidos municípios; 2) elaborar mapas temáticos que apresentem a espacialização da erosividade na área em estudo; e 3) analisar os níveis de erosividade das chuvas, identificando as áreas com maior potencial erosivo nos municípios de Castelo do Piauí e Juazeiro do Piauí.

\section{FUNDAMENTAÇÃO TEÓRICA}

O entendimento da dinâmica ambiental, considerando a maior parte de seus constituintes quando possíveis, é de suma importância para realização de prognoses e, ainda, para o planejamento físico-territorial.

O clima tem interferência direta sobre a dinâmica ambiental. Desse modo, ele é determinado, principalmente, pela circulação geral atmosférica, que resulta do aquecimento diferencial global pela radiação solar, da distribuição assimétrica de oceanos e continentes, bem como das características topográficas sobre os continentes (FERREIRA e MELLO, 2005). O clima de uma determinada região é composto por vários elementos, dentre eles destacam-se, de acordo com Torres (2008): a radiação solar, a temperatura, a umidade do ar, a pressão atmosférica, os ventos, a nebulosidade e a precipitação. 


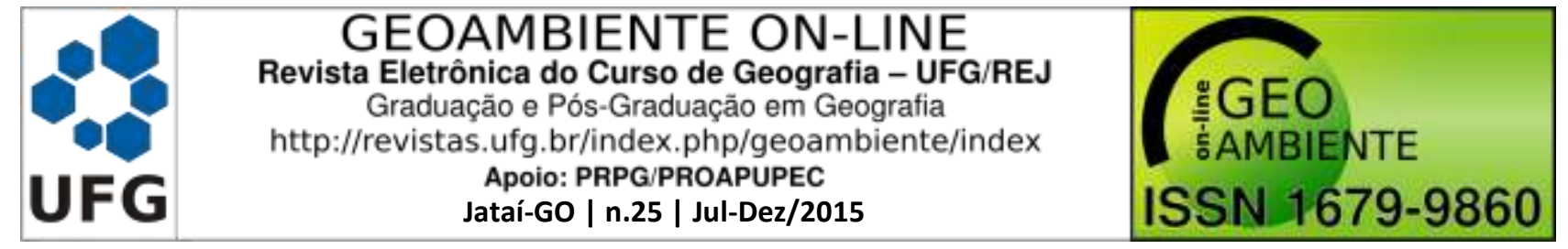

Nesse contexto climático, enfatiza-se a Zona de Convergência Intertropical (ZCIT), como sendo o mais importante fator que determina abundância ou deficiência de chuvas no setor Norte do Nordeste do Brasil, conforme propõe Ferreira e Mello (2005). Molion e Bernardo (2000) afirmam que a ZCIT é responsável pela ocorrência de chuvas de fevereiro a maio e anos de seca e seu bloqueio ao norte inibe a precipitação, deixando a referida zona debaixo de uma região de subsidência.

Para Molion e Bernardo (2000), a precipitação é a variável climatológica mais importante, porém, uma das mais difíceis de ser observada com precisão, pois apresenta erro instrumental, de exposição e de localização. A alta pluviosidade anual concentrada em curto período de tempo favorece a morfogênese e é responsável pela intensa denudação nas regiões semiáridas, cuja característica mais marcante são os afloramentos rochosos (FLORENZANO, 2008; VALERIANO, 2008).

A cobertura vegetal influi diretamente na diminuição da erosão, pela interceptação das precipitações e pelo favorecimento do surgimento de detritos vegetais à superfície do solo. Ressalte-se que ambos desempenham papel amortecedor ou absorvedor de energia, diminuindo a velocidade do vento e aumentando a turbulência da passagem do ar. Em áreas sem vegetação, o vento pode remover partículas minerais, gerando tempestades de pó e formando dunas, impondo severas limitações ao crescimento da vegetação (TRICART, 1977).

O clima tem influência direta nos processos erosivos de maneiras diversas. Contudo, um dos principais tipos de erosão diz respeito à erosão hídrica pluvial, que é causada pelo impacto das gotas da chuva no solo, quando ele se encontra desprovido de cobertura vegetal. Lombardi Neto e Moldenhauer (1992) definem Erosividade das chuvas como a perda de solo por unidade de área esperada de uma chuva ao cair em área desprovida de cobertura e resíduos vegetais.

A chuva é o principal agente causador de erosão nos solos. A perda de solos, por sua vez, é diretamente proporcional ao aumento das quantidades totais de chuvas, ou seja, a duração, a intensidade e a distribuição das chuvas interferem na intensidade e volume total da perda de solos por erosão (LOMBARDI NETO e PASTANA, 1972).

Para Lal e Elliot (1994), a Erosividade das chuvas diz respeito à capacidade dos agentes de erosão, como a água, de causar desprendimento do solo e transportá-lo. Carvalho et al. (2010) propõe que para mensurar a Erosividade é necessário determinar a média mensal do índice de erosão. Para Beltrame (1994), o referido parâmetro corresponde à quantidade de solo que se perde por efeito da erosão resultante da chuva. 


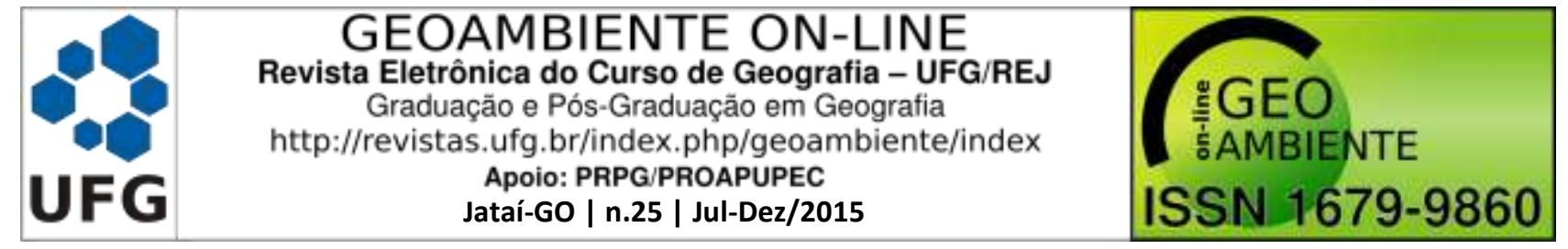

A intensidade das chuvas tem direta influência no aumento do risco de erosão, visto que chuvas com longa duração e baixa intensidade possibilitam perdas de água com pequeno risco de erosão, enquanto chuvas com menor quantidade e alta intensidade podem ocasionar maior risco. A possibilidade de serem avaliados os riscos de erosão que são esperados a partir das várias características das chuvas pode predizer os potenciais riscos de degradação de uma determinada área. Entretanto, os dados de chuvas totais ou médias mensais não devem ser considerados isoladamente, mas devem estar relacionados a outros elementos, tais como características do solo (LOMBARDI NETO e PASTANA, 1972).

Aquino et al. (2006) estimaram a Erosividade das chuvas nas terras secas do estado do Piauí por meio de método indireto. Seus resultados apontaram que 33\%, 58,7\%, $8 \%$ e 0,3\% do estado apresenta, respectivamente, erosividade muito baixa, baixa, média, e alta. Portanto, inferiu-se que $91,7 \%$ da área em estudo apresenta predomínio de valores de erosividade situados nas classes de muito baixa e baixa. Portanto, baixo potencial das chuvas pode causar erosão nas terras secas do referido estado.

Melo (2008) calculou o índice de R da Microbacia do Riacho dos Cavalos, em Crateús (CE), utilizando os dados de precipitação mensal dos postos pluviométricos. Assim, constatou que a área estudada apresenta apenas as classes de erosividade Alta, com aproximadamente $77,2 \%$ da área, e Moderadamente Alta, com 22,8\%. As maiores taxas de R foram encontradas para os meses de março e abril e os maiores valores para os meses de agosto a novembro.

Cabral et al. (2014) buscaram analisar o fator $\mathrm{R}$ de parte do alto curso do rio Banabuiu, localizado no sertão central do Ceará, utilizando o índice de Fournier. A partir dos dados de precipitação média considerando uma série histórica de 30 anos de 12 postos pluviométricos, foi possível inferir que os meses de julho a dezembro apresentaram os menores valores de $\mathrm{R}$, enquanto os meses de março e abril apresentaram os maiores índices de Erosividade, no qual a erosão dos solos é mais acentuada.

\section{PROCEDIMENTOS METODOLÓGICOS}

Devido à inexistência de pluviógrafos, que são utilizados para mensurar os valores de $\mathrm{R}$ em várias regiões brasileiras, falhas e defasagem na captação de dados, morosidade e trabalho para analisar os diagramas dos pluviógrafos, vários autores e o presente estudo utilizaram método indireto, como mostra a Equação 1 proposta por Lombardi Neto e Moldenhauer (1992). A referida equação representa a Erosividade da chuva e estima com relativa precisão os valores de $\mathrm{R}$ para longos períodos. A equação baseia-se em regressão 


\section{GEOAMBIENTE ON-LINE \\ Revista Eletrônica do Curso de Geografia - UFG/REJ \\ Graduação e Pós-Graduaçăo em Geografia \\ http://revistas.ufg.br/index.php/geoambiente/index \\ Apoio: PRPG/PROAPUPEC \\ Jataí-GO | n.25 | Jul-Dez/2015}

linear entre o índice médio mensal de erosão e o coeficiente de chuva, tendo boa aceitação entre os pesquisadores brasileiros.

$$
\mathrm{E}=67,355\left(\mathrm{r}^{2} / \mathrm{P}\right)^{0,85}
$$

Onde:

$\mathrm{E}=$ média mensal do índice de erosão (t/ha.mm/h);

$\mathrm{r}=$ precipitação média mensal em $\mathrm{mm}$;

$\mathrm{P}=$ precipitação média anual em $\mathrm{mm}$.

A análise do fator R para a área em estudo baseou-se nos dados de precipitações das séries anuais obtidas em SUDENE (1990) e empregados na metodologia de Thornthwaite (THORNTHWAITE e MATHER, 1955). Foram utilizados 13 postos pluviométricos situados no interior e entorno dos municípios de Castelo do Piauí e Juazeiro do Piauí, para análise do de R a partir de série histórica de 23 anos. As falhas encontradas nas referidas séries foram corrigidas pelo Método de Ponderação Regional proposto em Tucci (1993).

Os dados de ' $\mathrm{R}$ ' considerando o maior e o menor valores obtidos foram enquadrados em cinco classes de intervalos de igual amplitude, sendo posteriormente, atribuída a cada intervalo uma denominação, conforme indicado na Tabela 1:

Tabela 1: Intervalos de R com respectivas denominações das classes correspondentes a cada intervalo.

\begin{tabular}{c|c}
\hline $\begin{array}{c}\text { Amplitude de R } \\
\text { (MJ.mm/ha.h.ano) }\end{array}$ & Classe atribuída \\
\hline $\mathrm{R}<6.460$ & Muito Baixa \\
\hline $6.460<\mathrm{R}<6.840$ & Baixa \\
\hline $6.840<\mathrm{R}<7.220$ & Moderada \\
\hline $7.220<\mathrm{R}<7.600$ & Alta \\
\hline $\mathrm{R}>7.600$ & Muito Alta \\
\hline
\end{tabular}

Fonte: Pesquisa direta. Santos (Org.), 2015.

Os citados dados foram manuseados através do Sistema de Informação Geográfica (SIG) ArcGIS 10.2, utilizando o método de interpolação IDW (peso pelo inverso da distância) para interligar os dados das tabelas do programa Excel versão 2010 e gerar o Mapa de Erosividade das chuvas para os municípios estudados. 


\subsection{Localização e caracterização geoambiental da área em estudo}

O estudo foi desenvolvido nos municípios de Castelo do Piauí e Juazeiro do Piauí, localizados (Figura 1) na Macrorregião Meio-Norte, Território de Desenvolvimento dos Carnaubais e $6^{\circ}$ Aglomerado de Municípios (AGM) (PIAUÍ, 2006), cujas sedes municipais localizam-se, respectivamente, a $158 \mathrm{~km}$ e $184 \mathrm{~km}$ de Teresina. Os referidos municípios possuem importantes fontes historiográficas, registros fósseis, vegetação de transição caatinga arbustivo/arbórea, cerrado e carnaubal, com formações rochosas areníticas.

Figura 1: Localização dos municípios de Castelo do Piauí e Juazeiro do Piauí.

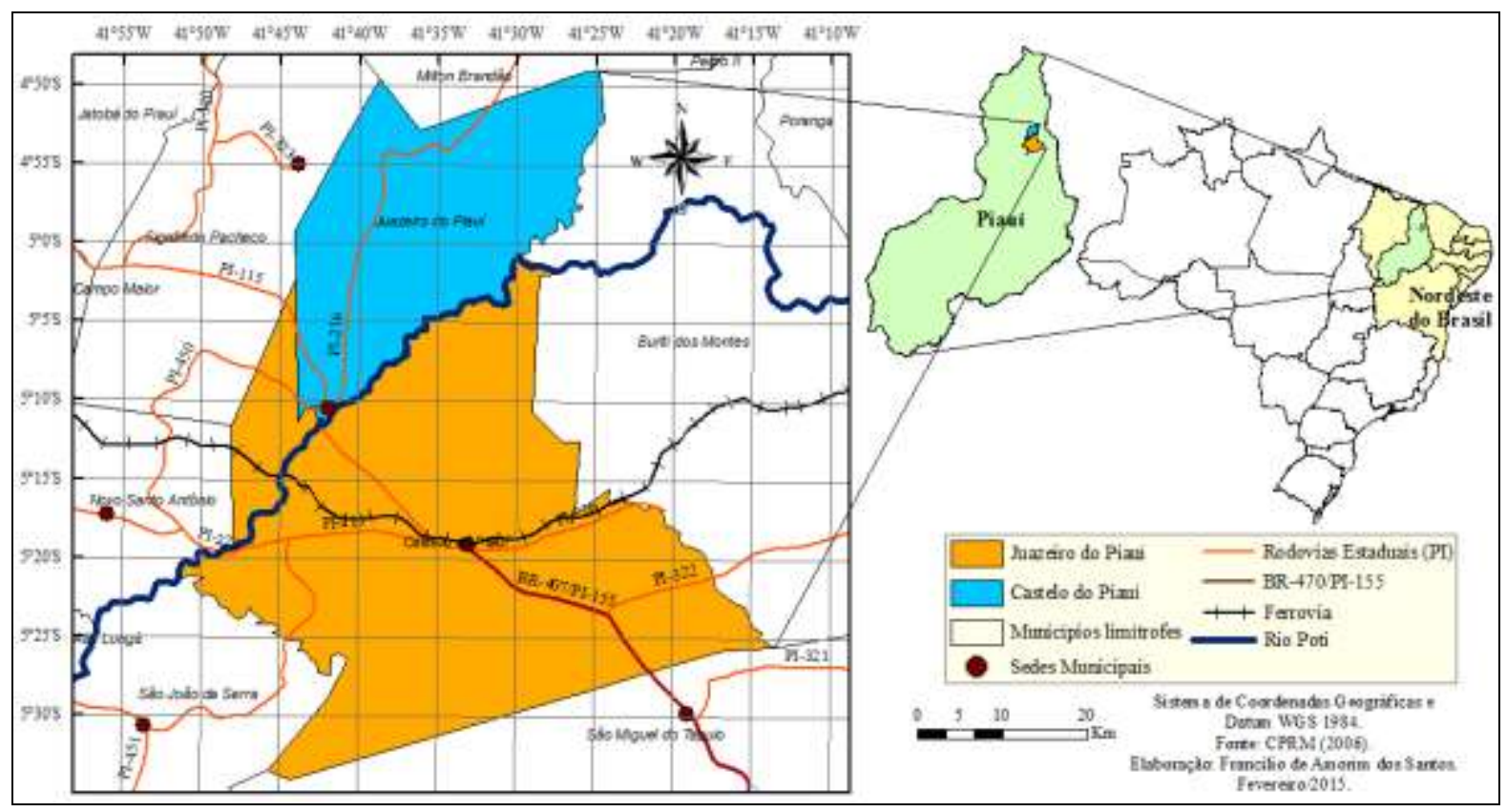

Fonte: CPRM (2006).

O município de Castelo do Piauí possui $2.035,2 \mathrm{~km}^{2}$ de extensão territorial, limitandose ao norte com Pedro II, ao sul com São Miguel do Tapuio, a leste Área de Litígio entre Piauí e Ceará, a oeste com Campo Maior, Alto Longá e São João da Serra. Sua sede municipal localiza-se às Coordenadas Geográficas: 05¹9'19'S e 41³3'10"O (AGUIAR e GOMES, 2004a; IBGE, 2014). Juazeiro do Piauí possui área de $827,2 \mathrm{~km}^{2}$, limitando-se ao norte com Sigefredo Pacheco e Milton Brandão, ao sul com Castelo do Piauí e Buriti dos Montes, a leste com Buriti dos Montes, a oeste com Castelo do Piauí e Sigefredo Pacheco; sua sede situa-se

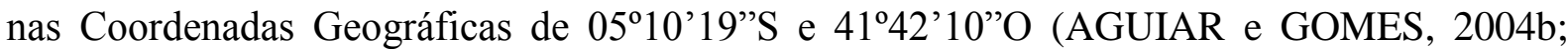




\section{GEOAMBIENTE ON-LINE \\ Revista Eletrônica do Curso de Geografia - UFG/REJ \\ Graduação e Pós-Graduaçăo em Geografia \\ http://revistas.ufg.br/index.php/geoambiente/index \\ Apoio: PRPG/PROAPUPEC \\ Jataí-GO | n.25 | Jul-Dez/2015}

IBGE, 2014). Deve-se destacar que ambos os municípios são separados pelo rio Poti, que é de suma importância para o desenvolvimento das atividades humanas nos referidos municípios.

\section{RESULTADOS E DISCUSSÃO}

O conhecimento do volume de precipitação de uma dada região é bastante importante, tanto para a prática de atividades agrícolas, quanto para determinar o nível de Erosividade das chuvas. Desse modo, a Precipitação Média Anual em Castelo do Piauí e Juazeiro do Piauí apresenta significativa variação, oscilando de $769 \mathrm{~mm}$ no posto Assunção a $1.369 \mathrm{~mm}$ no posto Alto Longá, com média pluviométrica geral de $996 \mathrm{~mm}$. A precipitação dos postos pluviométricos nos municípios estudados apresenta variabilidade média, o que pode ser observado pelo Coeficiente de Variação (CV). O menor valor do CV foi de 13,7\% no posto Alto Longá e o maior valor foi de $24,4 \%$ para o posto Assunção, conforme mostra a Tabela 2.

Através dos dados, presentes na Tabela 2, foi possível elaborar o mapa para espacialização das chuvas na área estudada. Portanto, os municípios apresentam os maiores índices pluviométricos situados entre 1.100 a $1.200 \mathrm{~mm}$ (Figura 2), correspondendo a 51,1\% da área estudada, especificamente, na parte centro-norte, esta sob influência da ZCIT. O segundo maior nível de precipitação corresponde ao intervalo de 1.000 a $1.100 \mathrm{~mm}$, abrangendo $23 \%$ dos municípios, região nordeste e sudoeste-sudeste da área estudada.

Tabela 2: Precipitação média e coeficiente de variação interanual das precipitações dos municípios de Castelo do Piauí e Juazeiro do Piauí.

\begin{tabular}{c|c|c}
\hline \multirow{2}{*}{ Postos } & \multicolumn{2}{|c}{ Precipitação } \\
\cline { 2 - 3 } & Média $(\mathbf{m m})$ & CV (\%) \\
\hline Alto Longá & 1.369 & 13,7 \\
\hline Castelo do Piauí & 1.132 & 16,6 \\
\hline Santana & 1.031 & 18,2 \\
\hline Pedro II & 1.324 & 14,1 \\
\hline Madeira Cortada & 853 & 22,0 \\
\hline Retiro & 1.044 & 18,0 \\
\hline Oitis & 964 & 19,5 \\
\hline São João da Serra & 1.012 & 18,5 \\
\hline Alívio & 840 & 22,3 \\
\hline Assunção & 769 & 24,4 \\
\hline Dico Leopoldino & 895 & 21,0 \\
\hline São Miguel do Tapuio & 852 & 22,0 \\
\hline São Vicente & 860 & 21,8 \\
\hline
\end{tabular}

Fonte: Pesquisa direta. Santos (Org.), 2015. 
Figura 2: Precipitação Total Média Anual dos municípios de Castelo do Piauí e Juazeiro do Piauí.

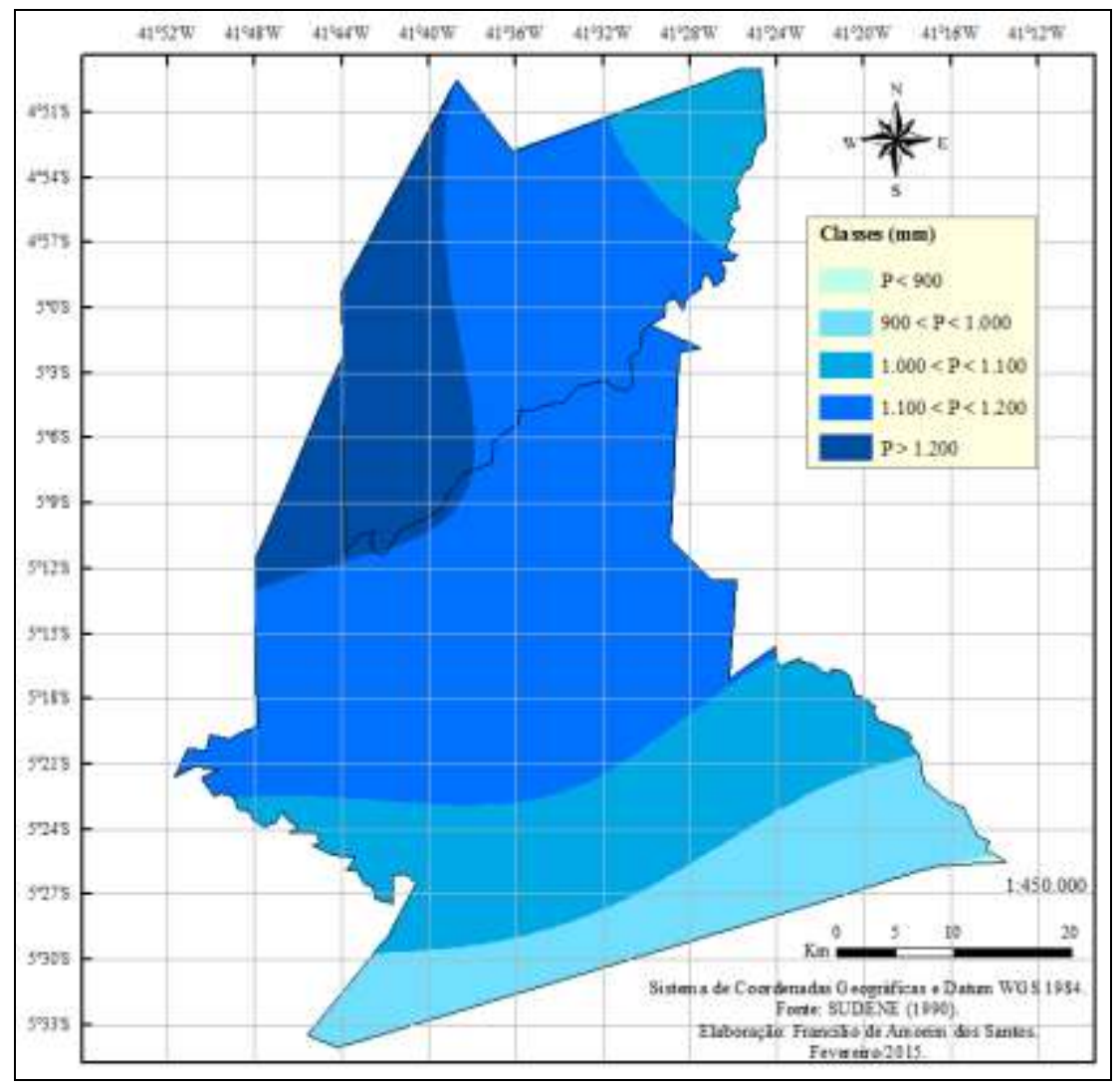

Fonte: Adaptado de SUDENE (1990).

Através da Tabela 3 pode-se afirmar que o posto com menor valor de $\mathrm{R}$ foi o de Assunção com 5.870 Mj.mm/ha.h.ano e o de maior valor foi o de Pedro II, que apresentou 8.874 Mj.mm/ha.h.ano. O período de maior Erosividade das chuvas concentra-se nos meses de janeiro a abril, devido à concentração das precipitações nos citados meses e influência da ZCIT, responsável pelas precipitações de fevereiro a abril.

A Tabela 3 permite afirmar que as médias de junho a novembro são muito baixas, por conta das baixas precipitações pluviométricas, pois a ocorrência das chuvas no Nordeste inicia em dezembro e aumenta de janeiro para maio. Entretanto, os meses de janeiro a maio apresentam os maiores valores de $\mathrm{R}$ e maior capacidade de erosividade. $\mathrm{O}$ mês de março foi o 
que apresentou maior potencial de R, os postos Pedro II e Santana apresentam os maiores valores para o mês em questão, respectivamente, com 2.838 e $2.620 \mathrm{Mj} . \mathrm{mm} / \mathrm{ha}$.h.ano.

Tabela 3: Erosividade (R) média mensal e anual dos postos do interior e do entorno dos municípios de Castelo do Piauí e Juazeiro do Piauí.

\begin{tabular}{|c|c|c|c|c|c|c|c|c|c|c|c|c|c|}
\hline \multirow{2}{*}{$\begin{array}{c}\text { Postos } \\
\text { pluviométricos }\end{array}$} & \multicolumn{13}{|c|}{ Erosividade Mensal e Anual (Mj.mm/ha.h.ano) } \\
\hline & Jan & Fev & Mar & Abril & Maio & Jun & Jul & Ago & Set & Out & Nov & Dez & Anual \\
\hline Alto Longá & 1.258 & 1.364 & 2.333 & 2.320 & 428 & 23 & 14 & 7 & 7 & 32 & 101 & 464 & 8.351 \\
\hline Castelo do Piat & 1.044 & 1.334 & 2.443 & 2.170 & 236 & 15 & 6 & 2 & 2 & 16 & 64 & 372 & 7.644 \\
\hline Santana & 675 & 878 & 2.620 & 1.813 & 516 & 118 & 26 & 13 & 6 & 3 & 37 & 122 & 6.827 \\
\hline Pedro II & 41 & 1.801 & 2.838 & 2.520 & 507 & 53 & 13 & 1 & 4 & 10 & 23 & 163 & 8.874 \\
\hline Madeira Cort & 668 & 903 & 1.946 & 1.729 & 447 & 47 & 8 & 2 & 4 & 9 & 23 & 132 & 5.918 \\
\hline Retiro & 967 & 1.303 & 1.222 & 2.170 & 305 & 16 & 4 & 1 & 2 & 10 & 48 & 305 & 7.253 \\
\hline Oitis & 948 & 1.293 & 1.467 & 1.305 & 134 & 27 & 5 & 1 & 4 & 84 & 170 & 527 & 5.965 \\
\hline São João da S & 1.118 & 1.499 & 2.035 & 1.185 & 262 & 7 & 1 & 1 & 1 & 15 & 123 & 432 & 6.679 \\
\hline Alivio & 683 & 911 & 2.088 & 1.726 & 174 & 8 & 2 & - & 6 & 15 & 62 & 265 & 5.943 \\
\hline Assunção & 510 & 933 & 1.867 & 2.184 & 135 & 19 & 2 & 0 & 1 & 11 & 33 & 175 & 5.870 \\
\hline Dico Leopoldino & 1.001 & 1.023 & 1.834 & 1.610 & 119 & 11 & 10 & 0 & 3 & 25 & 109 & 312 & 6.057 \\
\hline $\begin{array}{l}\text { São Miguel do } \\
\text { Tapuio }\end{array}$ & 902 & 1.140 & 1.821 & 1.747 & 155 & 10 & 2 & 0 & 2 & 13 & 40 & 261 & 6.093 \\
\hline São Vicente & 783 & \begin{tabular}{|l|l|}
1.197 \\
\end{tabular} & 1.616 & 1.813 & 170 & 12 & 3 & 0 & 4 & 20 & 57 & 291 & 5.966 \\
\hline
\end{tabular}

Os dados obtidos são semelhantes aos encontrados em Aquino (2010), cuja maior concentração de erosividade deu-se nos meses de novembro a abril. Os resultados de Cabral et al. (2014), também, são semelhantes, posto que seus dados apontem que as médias de julho a dezembro são muito baixas, cuja erosividade aumenta a partir desse último mês e estende-se de janeiro a maio, destacando-se os meses de março e abril como tendo maiores valores de $\mathrm{R}$ e, consequentemente, maior capacidade erosiva das chuvas. Cite-se, ainda, o estudo de Melo (2008) que apontou os meses de março e abril como possuidores de maiores valores R.

Por meio da Figura 3, pode-se afirmar que os municípios de Castelo do Piauí e Juazeiro do Piauí apresentam a maior parte de seus territórios situados nas classes alta a muito alta de Erosividade das chuvas. Os referidos municípios apresentam 74,7\% de suas áreas classificadas como de alta a muito alta erosividade, enquanto apenas $11,9 \%$ representam muito baixa a baixa erosividade (Tabela 4$)$.

A Figura 4 relaciona os dados médios mensais de Precipitação $(\mathrm{P})$ e Erosividade das chuvas, da série histórica de 23 anos. Pode-se afirmar que o período de maior Erosividade das chuvas concentra-se nos meses de janeiro a abril. 
Figura 3: Erosividade das chuvas dos municípios de Castelo do Piauí e Juazeiro do Piauí.

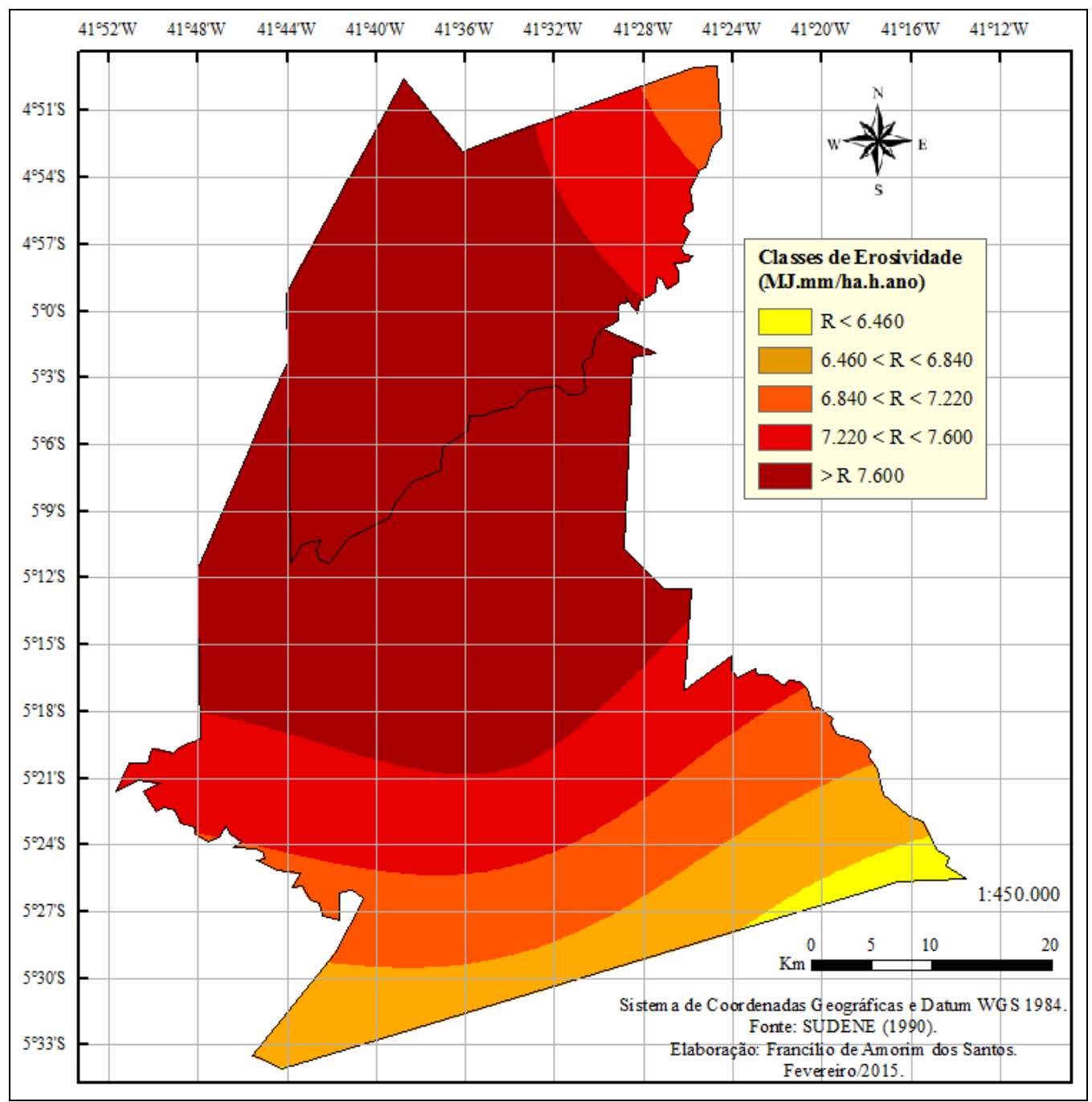

Fonte: Adaptado de SUDENE (1990).

Tabela 4: Intervalos e classes de Erosividade (R) com respectivas áreas em porcentagens, em Castelo do Piauí e Juazeiro do Piauí.

\begin{tabular}{c|c|c|c}
\hline Intervalos & Classes de Erosividade & Área & \% \\
\hline $\mathrm{R}<6.460$ & Muito Baixa & 37,2 & 1,3 \\
\hline $6.460<\mathrm{R}<6.840$ & Baixa & 303,4 & 10,6 \\
\hline $6.840<\mathrm{R}<7.220$ & Moderada & 383,6 & 13,4 \\
\hline $7.220<\mathrm{R}<7.600$ & Alta & 592,5 & 20,7 \\
\hline $\mathrm{R}>7.600$ & Muito Alta & $1.545,7$ & 54 \\
\hline Total & - & $\mathbf{2 . 8 6 2 , 4}$ & $\mathbf{1 0 0}$ \\
\hline
\end{tabular}

Fonte: Pesquisa direta. Santos (Org.), 2015. 
Figura 4: Médias de Precipitação mensal (P) e Erosividade das chuvas (R) referentes aos postos pluviométricos dos municípios de Castelo do Piauí e Juazeiro do Piauí.

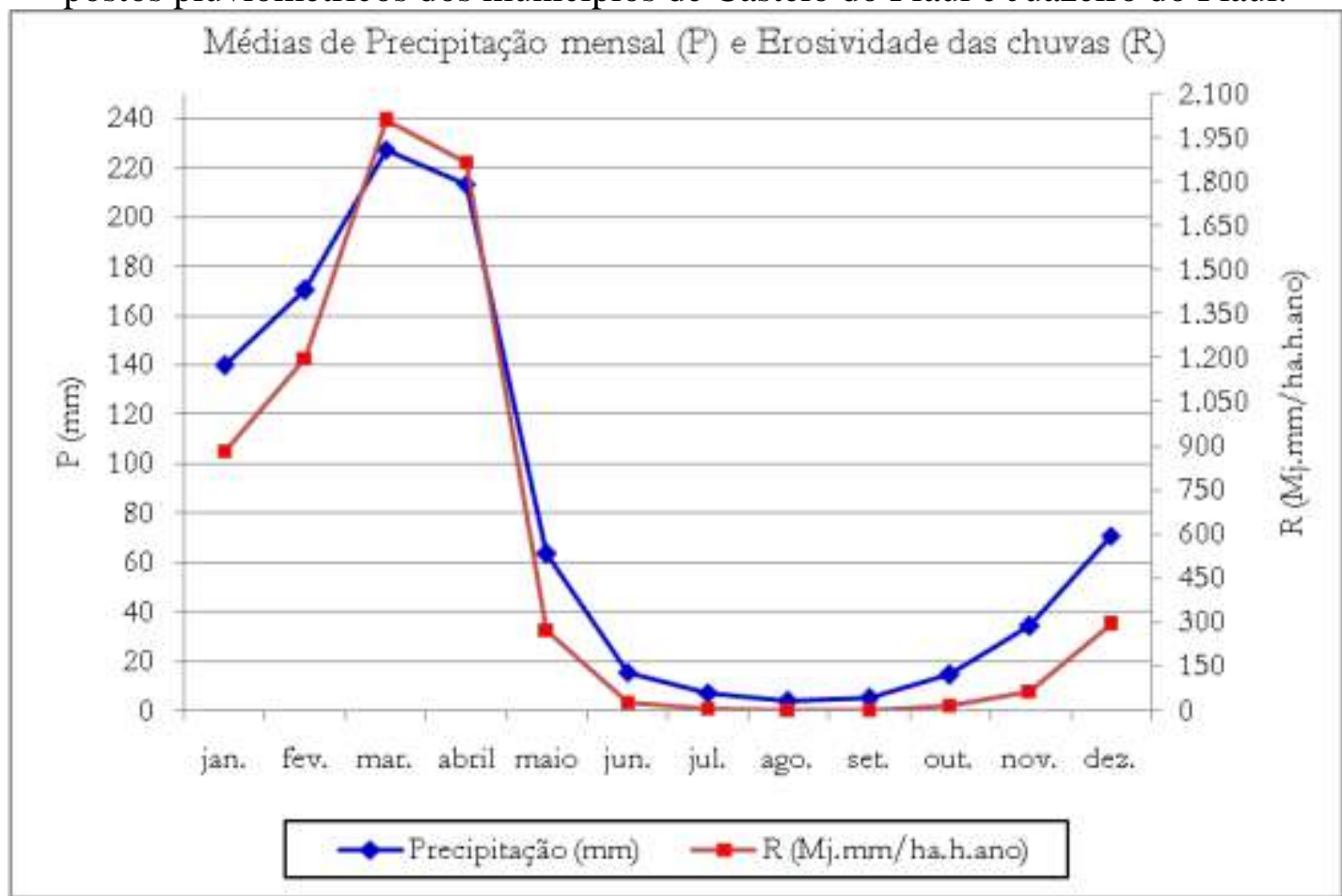

Fonte: Pesquisa direta. Santos (Org.), 2015.

A vegetação presente nos municípios de Castelo do Piauí e Juazeiro do Piauí é constituída por variadas fisionomias em diversos estágios de conservação e de regeneração. A estrutura vegetacional da área apresenta formações baixas e abertas, destacando-se o estrato herbáceo e arbóreo mais encorpado, o cerrado rupestre encontra-se disposto sobre os afloramentos rochosos (Figura 5) e entre as linhas de drenagem temporárias, caracterizandose por possuir plantas de pequeno porte e bastante espaçadas (ALBINO, 2005). Destacam-se, ainda, extensas áreas planas com solos expostos recobertos por pedregosidade ou com carnaubal (Figura 6). 


\begin{tabular}{|c|c|c|}
\hline $1 E$ & $\begin{array}{c}\text { GEOAMBIENTE ON-LINE } \\
\text { Revista Eletrônica do Curso de Geografia - UFG/REJ } \\
\text { Graduaçăa e Pós-Graduaçáo em Geografia } \\
\text { http://revistas.ufg.br/index.php/geoambiente/index } \\
\text { Apoio: PRPG/PROAPUPEC } \\
\text { Jatai-GO | n.25 | Jul-Dez/2015 }\end{array}$ & $\begin{array}{l}\text { İGEO } \\
\text { İAMBIENTE } \\
\text { ISSN } 1679-9860\end{array}$ \\
\hline
\end{tabular}

Figura 5: Afloramento rochoso com cerrado rupestre às margens do rio Poti.

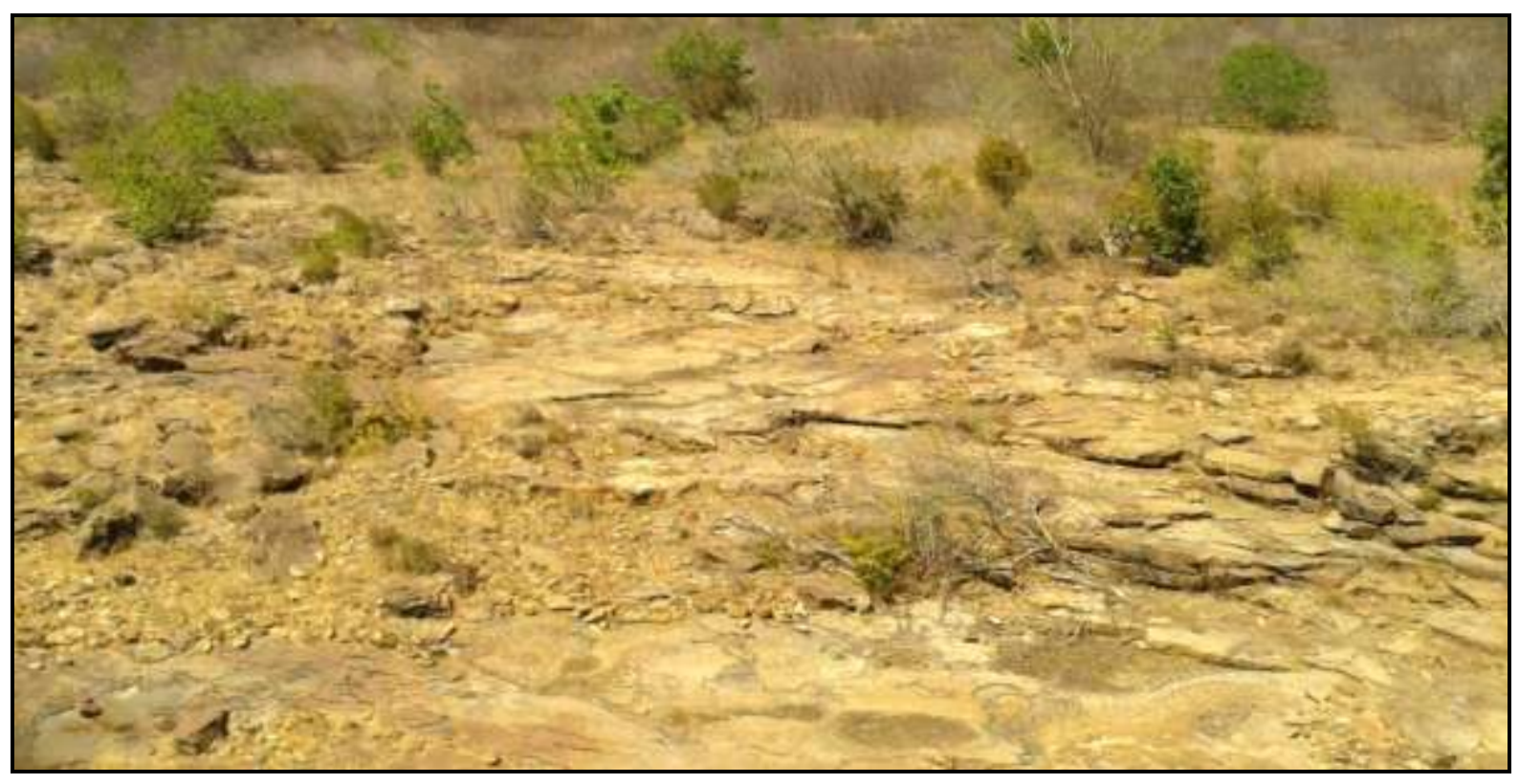

Fonte: Arquivo do autor (2015).

Figura 6: Solo exposto, recoberto por pedregosidade e ao fundo vegetação do tipo caatinga arbustiva nos Patamares Estruturais da Bacia do rio Poti.

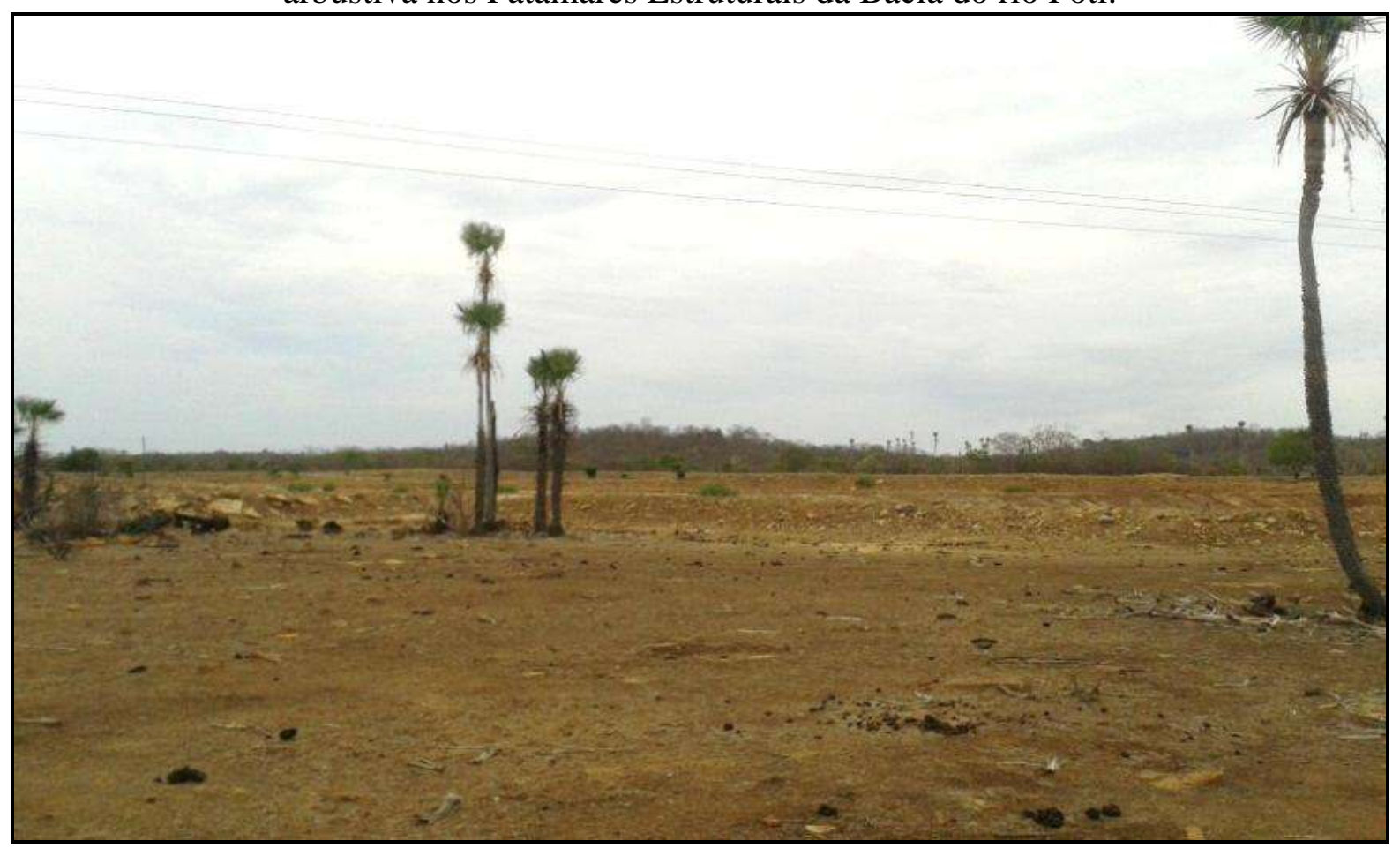

Fonte: Arquivo do autor (2015). 


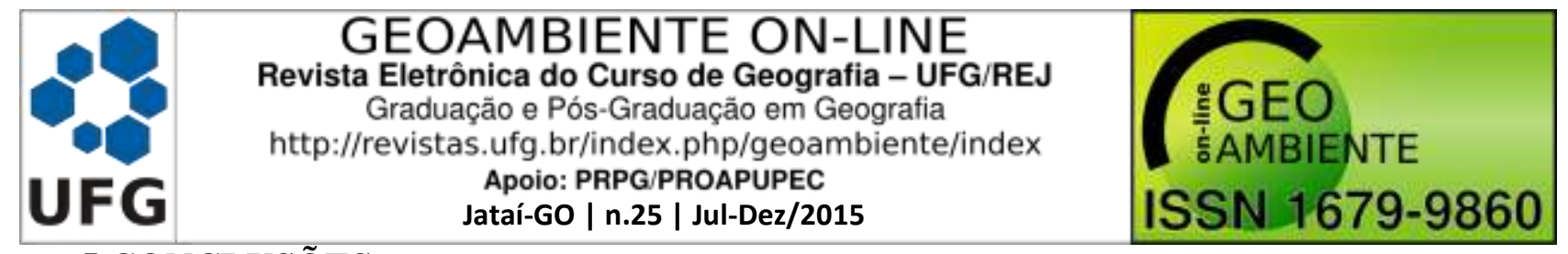

\section{CONCLUSÕES}

As práticas humanas aliadas à dinâmica natural, em especial em áreas com fragilidade natural, podem resultar no desencadeamento do processo de degradação ambiental. Desse modo, através dos dados aqui apresentados foi possível analisar a variação da precipitação para os municípios de Castelo do Piauí e Juazeiro do Piauí.

Pode-se constatar que $51,1 \%$ da área dos municípios estudados possuem taxas pluviométricas situadas entre 1.100 a $1.200 \mathrm{~mm}$, e estão em parte do ano sob influência da ZCIT. Em 11,9\% da área os valores de erosividade permitem enquadrá-las nas classes de muito baixa a baixa erosividade das chuvas. Em 74,7\% da área dos municípios constataram-se valores de erosividade variando de alta a muito alta Erosividade e, portanto, elevado risco de erosão hídrica pela ação das chuvas.

Ressalta-se que o potencial de risco de erosão pela chuva, aqui analisado a partir do fator Erosividade, decresce no sentido Norte devido às baixas taxas de precipitação. Diante do exposto, os dados visualizados permitem identificar áreas com menores riscos à erosão resultantes da chuva e ainda áreas com maiores riscos a erosão, considerando o fator erosividade da chuva. Por outro lado, há necessidade de entendimento e análise de outros fatores geoambientais e socioeconômicos para uma inferência mais completa acerca das condições de fragilidade mais próximas da realidade.

\section{REFERÊNCIAS}

AGUIAR, R. B.; GOMES, J. R. C. (Org.). Projeto cadastro de fontes de abastecimento por água subterrânea, estado do Piauí: diagnóstico do município de Castelo do Piauí. Fortaleza: CPRM - Serviço Geológico do Brasil, 2004a.

. Projeto cadastro de fontes de abastecimento por água subterrânea, estado do

Piauí: diagnóstico do município de Juazeiro do Piauí. - Fortaleza: CPRM - Serviço Geológico do Brasil, 2004b.

ALBINO, R. S. Florística e fitossociologia da vegetação de cerrado rupestre de baixa altitude e perfil socioeconômico da atividade mineradora em Castelo do Piauí e Juazeiro do Piauí, Brasil. Dissertação (Mestrado em Desenvolvimento e Meio Ambiente). Universidade Federal do Piauí - UFPI. Teresina, 2005.

AQUINO, C. M. S. Estudo da degradação / desertificação no núcleo de São Raimundo Nonato - Piauí. Tese (Doutorado em Geografia). Universidade Federal de Sergipe - UFSE.

São Cristovão, 2010. 


\begin{tabular}{|c|c|c|}
\hline & $\begin{array}{c}\text { GEOAMBIENTE ON-LINE } \\
\text { Revista Eletrônica do Curso de Geografia - UFG/REJ } \\
\text { Graduação e Pós-Graduaçäo em Geografia } \\
\text { http://revistas.ufg.br/index.php/geoambiente/index } \\
\text { Apoio: PRPG/PROAPUPEC } \\
\text { Jataí-GO | n.25 | Jul-Dez/2015 }\end{array}$ & $\begin{array}{l}\text { ¿GEO } \\
\text { 亡.AMBIENTE } \\
\text { ISSN } 1679-9860\end{array}$ \\
\hline
\end{tabular}

AQUINO, C. M. S.; OLIVEIRA; J. G. B.; SALES, M. C. L. Estimativa da erosividade das chuvas (R) nas terras secas do Estado do Piauí. Revista Ciência Agronômica, v.37, n.3, 2006. p.287-291.

CABRAL, L. J. R. S.; VALLADARES, G. S.; AQUINO, C. M. S. Erosividade das chuvas em parte do alto curso do rio Banabuiu - sertão central do Ceará. Revista Equador (UFPI), Vol.3, n², Julho/Dezembro, 2014. p.51-61.

CPRM - Companhia de Pesquisa de Recursos Minerais. Ministério de Minas e Energia. Mapas estaduais de geodiversidade: Piauí. Rio de Janeiro: CPRM. 2006. Documento cartográfico em arquivo vetorial. Disponível em http://geobank.sa.cprm.gov.br. Acesso em janeiro de 2014.

CREPANI, E.; MEDEIROS, J. S.; HERNANDEZ FILHO, P.; FLORENZANO, T. G.; DUARTE, V.; BARBOSA, C. C. F. Sensoriamento Remoto e Geoprocessamento Aplicados ao Zoneamento Ecológico-Econômico e ao Ordenamento Territorial. São José dos Campos: INPE, 2001. 124p.

FERREIRA, A. G.; MELlO, N. G. S. Principais sistemas atmosféricos atuantes sobre a região Nordeste do Brasil e a influência dos Oceanos Pacífico e Atlântico no clima da região. Revista Brasileira de Climatologia, Vol. 1, № 1, p.15-28. Dezembro de 2005.

FLORENZANO, T. G. Cartografia. In: FLORENZANO, T. G. (Org.). Geomorfologia: conceitos e tecnologias atuais. São Paulo: Oficina de Textos. 2008.p.105-128.

IBGE - Instituto Brasileiro de Geografia e Estatística. Ministério do Planejamento, Orçamento e Gestão. Manual Técnico de Pedologia. $2^{\text {a }}$ edição. Rio de Janeiro, 2007.

JACOMINE, P. K. T. Mapa exploratório-reconhecimento de solos do estado do Piauí. Convênio EMBRAPA/SNLCS-SUDENE-DRN. 1983.

LAL, R.; ELLIOT, W. Erodibility and erosivity. In: LAL, R. Soil Erosion: research methods. Second Edition.Ankeny: Soil and Water Conservation Society, 1994.p.180-208.

MELO, E. T. Diagnóstico Físico Conservacionista da Microbacia do Riacho dos Cavalos Crateús - Ceará. Dissertação (Mestrado em Desenvolvimento e Meio Ambiente). Universidade Federal do Ceará - UFC. Fortaleza, 2008.

MOLION, L. C. B.; BERNARDO, S. O. Dinâmica das Chuvas no Nordeste Brasileiro. In: Anais do XI Congresso Brasileiro de Meteorologia (CD-Rom), p.1.334-1.342. Rio de Janeiro, 2000.

SUDENE. Dados Pluviométricos Mensais do Nordeste: Estado do Piauí. Recife, 1990. 


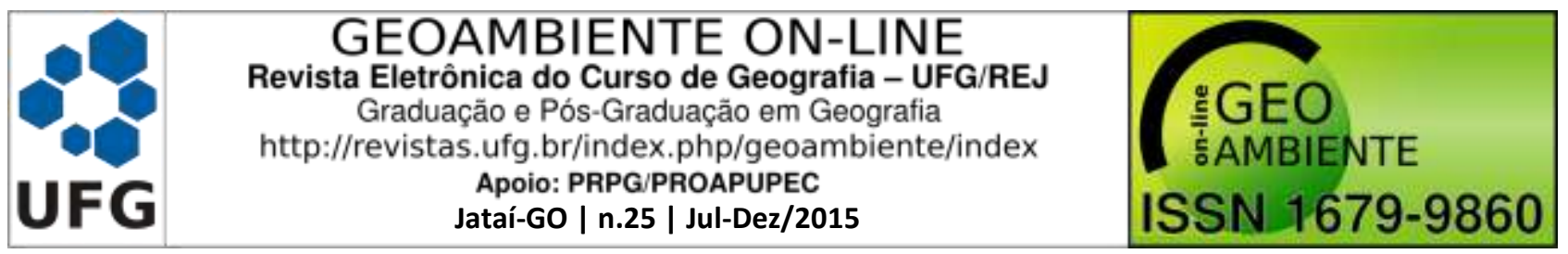

THORNTHWAITE, C. W; MATHER, J. R. The Water Balance - Publications in Climatology. New Jersey: Centerton, v. VIII, nº 1, 1955.

TORRES, F. T. P. Introdução à Climatologia. - Ubá/MG: ed. Geographia consultoria, estudos e projetos ambientais 1tda., 2008. (Série Textos Básicos Geografia).

TRICART, J. Ecodinâmica. Rio de Janeiro, IBGE, Diretoria Técnica, SUPREN, 1977.

TUCCI, C. E. M. Hidrologia: ciência e aplicação. Porto Alegre: Eds. da UFRGS e da USP, 1993. (Coleção ABRH de Recursos Hídricos, v. 4). 952p.

VALERIANO, M. M. Dados Topográficos. In: FlOREnZANO, T. G. (Org.). Geomorfologia: conceitos e tecnologias atuais. São Paulo: Oficina de Textos. 2008, p.72-104. 